\title{
Perspectives about Living and Aging for the Manager of a Familiar Company
}

\author{
Mariane Luiza Mattjie1, Adriano Pasqualotti2,3, Fausto Amaro3 \\ ${ }^{1}$ Psichology Department, Faculdade Meridional, Passo Fundo, Brazil \\ ${ }^{2}$ University of Passo Fundo, Passo Fundo, Brazil \\ ${ }^{3}$ University of Lisbon, Lisbon, Portugal \\ Email: mariane.mattjie@imed.edu.br
}

Received 24 January 2015; accepted 8 February 2015; published 11 February 2015

Copyright (C) 2015 by authors and Scientific Research Publishing Inc.

This work is licensed under the Creative Commons Attribution International License (CC BY). http://creativecommons.org/licenses/by/4.0/

(c) (i) Open Access

\begin{abstract}
In this study, we seek to reveal the perspectives, motivations and challenges of the managers of familiar company regarding succession. The sample consisted of six participants chosen by convenience and divided into two groups: entrepreneur managers with successors and without successors. The data analysis is the analysis of the participants' narratives. The results indicate that there are differences in the process of perceiving aging by the managers with and without successors. The entrance of the descendants in the management of the company transforms the activities of the patriarchs. The choice of getting away from the professional activities and passing the "baton" to the successor is related to becoming ill. Management problems interfere in the subject's life that cannot see leisure possibilities. It was observed that living and aging to these subjects is associated to maintaining the quality in family ties.
\end{abstract}

\section{Keywords}

Psychology, Human Development, Aging, Organization and Management, Decision-Making

\section{Introduction}

Aging is a continuous process, present to all living beings, since birth. However, it can still be seen as a path full of enigmas to be unraveled by all areas of science. When we mention aging through the prism of psychology, questions related to lifecycle and human development come to mind, both composed of phases and specific characteristics that require the individual, through its life, to change and adapt to new realities and conditions.

The aging process of the manager is characterized by personal and professional life stories intimately tied, incapable of being separated, which seems to distance the possibility of leaving the professional activity, and it is 
accompanied by unique elements that lead the manager, throughout his life course, to face conflicts that circulate between reason and emotion, making family and business to become interrelated.

As organisms that constitute and are constituted concomitantly through social relationships, the family institution and the business are very rich environments to be explored, in various areas. The organizational environment characterized as being family-managed is composed of costumes, habits, values, rules and regulations constituted by the culture of the manager disseminated amongst the internal relations and perceived even in the services offered to clients. There's a need for understanding the aging process of the manager and the elements triggered by it, among which we highlight the succession one. It is a delicate issue that requires, of those involved, planning and preparation, guaranteeing the sustainability of the familiar company and the maintenance of the affective relations.

Taking into account that in Brazil, people are considered to be elderly when they are 60 years old or older, this term will be used when referring to studies and bibliographical references about these subjects, although, this study did not confine itself to the elderly people, considering that we understand that aging is a process and not a stage and it does not precede a determined chronological age to begin, as well as the questions related to the succession in the companies follows along the subjects of all ages that can, since long before becoming an elderly, have to position before the family, the businesses, their own fears and uncertainties.

Studying the processes of aging in the light of psychology and of the sociological theories of aging, it is intended to contribute with the development of the knowledge on these themes, as well as to assist the subjects to live this process in a natural way, obtaining knowledge from the challenges present on them. It is also important in the current situation that the professionals from different areas of knowledge reflect about the issues of this study and deepen them, seeking to qualify themselves, even more, to exercise their activities with the elderly people, which represent a group growing significantly in our society and in the management of companies of all segments, mainly the family ones.

The objective of this study was to analyze the perspectives, motivations and challenges of familiar company managers concerning the succession process. It sought to understand the existence or not of differences in the managers' perception regarding aging.

\section{Materials and Method}

The study is characterized as qualitative. The sample of the research was constituted of six managers of familiar companies, all male, fifty years old or older, and that work in familiar companies in northern Rio Grande do Sul. The inclusion criteria of the subjects that were part of the research, in which the selecting process happened by convenience, was composed of managers that have family member(s) working in the management of the company and, managers that do not have family member(s) participating in the management of the company. Each group was composed of three subjects. The participants were men, with ages between 50 - 83 years old. All of them were married and had at least one descendant. They had a company in which they were founders and managers for at least twenty years.

The data were collected using the stimulus of slides with picture that symbolized the factors present in the living and aging processes of the manager of the familiar company, such as, picture of successful youngsters, family, leisure, elderly people, money and power, in the initial phase of the narrative interview. The pictures shown to the subjects aimed to demonstrate to the manager of the familiar company the theme concerned to the study, and made it possible for the answers to the questions of the problematic of the research to arise during the narrative process.

The method used for the research data analysis was Schutze's (1979) narrative analysis. The data were analyzed by means of the application NVivo 10 (2010), which generated similarity knots and narrative correlations of the interviewed subjects. The research project was approved by Research Ethics Committee of the University of Passo Fundo, Passo Fundo, Rio Grande do Sul, Brazil, CAAE 0158.0.398.000-11, notice 350/2011.

\section{Results and Discussions}

\subsection{Similarities between Managers}

The perceptions of the managers regarding the process of living and aging, going through the succession dilemma in the company, were structured in seven emerging subcategories: 1) work, employment and financial capac- 
ity of the familiar company; 2) familiar company and original family; 3) sons, daughters and finitude; 4) descendants' and manager's academic background; 5) leisure, free time and management problems; 6) living and aging process and family problems; 7) personal health and succession (Figure 1).

\subsection{Work, Employment and Financial Capacity of the Familiar Company}

For the manager of the familiar company the possibility of getting away from the company's activities, process which would lead to retirement is strictly linked to the company's financial capacity. The manager glimpses at the possibility of getting away from the activities, as long as the company's financial conditions allow him to do so. However, this is one of the reasons why retirement is far from becoming a reality. The manager concerns with the maintenance of the profits from the business. Only then does he opt for a safer and more comfortable option for leaving the professional activity and dedicating himself to leisure and other non-formal activities. The business financial capacity provides the managers a safer condition to provide his family with, as observed in the following quote:

[MWS-1] I did too well... There was never money lacking in my pocket. If my wife needed money, I had it.

On the other hand, it was observed that aging brings a more conservative behavior from the manager. When in old age, the person is more concerned in keeping what was conquered and does not yearn for new business's acquisitions, such as material possessions or investments of financial risk, as observed in the following quote:

[MWS-1] Nowadays, I don't have the courage to risk anything.

The processes of succession and the manager's withdrawal can be seen as some of the most significant changes occurring in the companies' and organizations' realities. The people who manage this process have to prepare themselves to deal with the changes. The fact that the company keeps the manager centralized in the management and that it holds the placement of "no change, no risk" can inclusively compromise the structure of the company in the long term, changing that is constant in the globalized world. According to Pinto and Coutode-Souza (2009), many companies are restructuring due to the new challenges, and the ones that are incapable of adapting face serious surviving problems. The involvement of talented and committed people conducting these changes, with substantial allocated resources for this effort and highly interested in taking risks, does not guarantee its efficiency. This fact makes it important the search for tools that assist the manager in this inevitable and risky process.

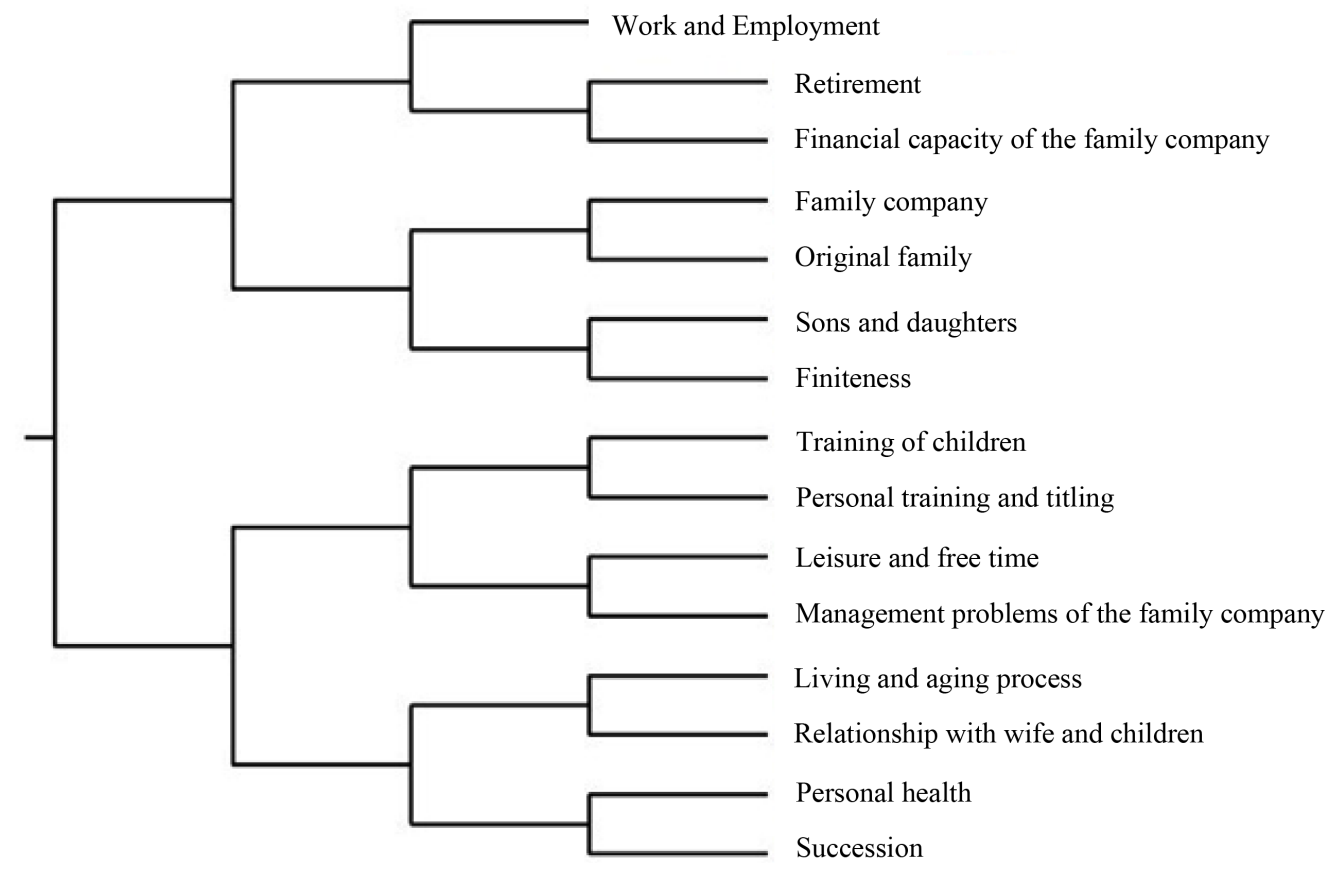

Figure 1. Cluster diagram of the codification similarity of the defined knots for the narrative analysis. Metric used for similarity: Pearson coefficient of linear correlation. 
The idea of retirement can also be associated with the reduction of the financial resource, a fact that for the majority of the population is a reality, being the subject either a public servant, or a private employee or the owner of his own business, the reduction of the work shift is an inherent factor. When the manager does not possess a familiar successor for the business, because the descendants are already working in other professional activities not related to the company's activity, they wish to reduce the workload, as observed in the following quote:

[MWOS-1] At one time we are going to reduce our activities... It is not just because of the money, we need to have time to rest. We will not be able to endure this rhythm for much longer, we are going to have to "take it easy".

Therewith, it can be understood that there is an idea associated to the withdrawal of the professional activities for a gain of leisure and resting time. Nevertheless, there is the concern with the monetary income that provides financial sustentation to the family, in many cases even for the descendants that do not possess financial independence yet.

\subsection{Familiar Company and Original Family}

There is a correlation in the narratives of the subjects interviewed which allowed the identification of an association between the familiar company and its stories alongside with the original family ones. It was possible to identify that there is close relationship between the remaining experiences in the original family with the present perception about the familiar company. This result can be exemplified in the quotes of two managers participating in the study, who recognized the role and the influence of their original families, in the professional initiation. The original family appears in a relevantly manner in the subjects' narrative when solicited to talk about the family's business. The existing tendency of replicating the positive experiences lived by the progenitors to the descendants can be pointed out, as observed in the following quote:

[MWS-3] I always wanted to do it like my father did, putting it in the office to acquire knowledge, mainly of the clientele.

This thought that origins an integration behavior from the descendant to the company indicates a manager's personal value that brings to the present a previous experience that was satisfactory and full of significances to him. Pinto and Couto-de-Souza (2009), state that the change inside the organizations points out that there is strong influence exerted by the director's personality and his centralized manner in the decentralization process, and therewith in the succession. It can be observed the manner the original family conducted the subject's initiation in the professional activities, exerting influences in the manner of how the manager conducts/conducted the insertion of the descendants in the business. The experience lived served as a model for the manager to be followed, for it refers to the support the family offered to his initiation, as identified in the following quote:

[MWS-2] I used to work at a quarry, but it was too tough because I was very young. So, my father managed to get me a job at the mechanics, but in that time nobody cared about the salary, boys, you know! What happened was that my father had to get a salary, take his money off and give the boss the money hidden from me, for the boss to give me.

[MWS-3] I started working with my father when I was 13 at a dispatcher's office. When I turned twenty, he gave me the office. He gave me all of it, social contract and everything. I had $100 \%$ autonomy. I changed the headquarters and increased the number of employees.

Martins, Maccari, Campanario and Almeida (2008) state that in the succession it is considered the tendency that the older son must take over the businesses in place of the progenitor. However, not always is the issue of the successor selection relative to the gender or birth order as a criterion. The lack of planning in the succession process and interrogations about the legitimacy of who the successor will be can neglect taking into account the yearnings of family members and of the clients. The authors, yet, evidence that in many companies there are not defined strategic business objectives, for everything seems to develop as a natural process resulting from family growth.

\subsection{Sons, Daughters and Finitude}

Managers that believe their sons will be their successors express the yearning of the continuity of the businesses. They think that it will not be necessary for them to resign completely from the company, at such a point that they will not have information about the activities of the company, but that they will perform other routines that 
are not so stressful or that, nowadays, cause them emotional exhaustion. When referring to the insertion of the descendants in the management of the business, the interviewees indicate the importance given to knowing the clients and the establishment of relationships with key people related to the activities performed, such as, partners, service providers and clients. They believe these contacts are fundamental to the resolution of the company's problems and the progress of activities. They identify the importance of developing, in the descendants, not only the technical knowledge of "knowing what to do" but of becoming personal reference for the contact groups, as observed in the following quote:

[MWS-3] I set my older son to learn the bases of the business... When I started working with my father I also did that. After I worked in this activity (going to the bank, to the accountant, to the client) for two years and some time was that I started working inside the company, but then the client would arrive at the office and I would already have a good relationship with him. I made sure to copy this format because I thought it worked really well. First, this interaction with the clients, this friendship we establish and then, the service provision itself.

In this aspect, the data presented are in agreement with Freire and Soares (2010), who state that the competence that has biggest role in succession is the knowledge of the company and of the business in its entirety. Yet, according to the authors, the individual competences that contribute the most for the adequate management of a company belong, in their majority, to the affective and cognitive domains. Martins et al. (2008) state that the entrance of new family members in the management of the company can happen without formal planning, as well as the lack of basic rules in the Human Resources Management, especially for the management or senior positions. It can be observed that the rules for hiring family members are not defined and not even are the functions they must exert. The authors still point out that few are the companies that survive the following generation, stating that there are difficulties encountered in the management of the familiar company and in the members' transition, mainly the ones pertaining to the third generation.

For Martins et al. (2008), the transition to the third generation is strongly associated to the company-family relation in what the following factors are concerned: 1) succession process influenced by familiar and emotional values; 2) conflicts, rivalries, strategic view divergences and divergences of company targets among the generations; 3) lack of professional criteria for hiring family members to the company; 4) communication fragility and, consequently, information asymmetry among the family members. On the other hand, thinking about diminishing the working activities and increasing leisure hours is also associated to the descendants, once that "sharing" some responsibilities can provide more free time, as observed in the following quote:

[MWS-3] Their (the descendants') entrance modified my activities a lot, because due to the quantity of clients that I have, I made sure to give them some of these clients. So, my workload reduced.

Paulo (2009) points out that the entrepreneurs, even those not aiming to resign from the company soon, wish to work on support functions and that it is a plan for many of these managers to be beside their successors, for they believe this learning experience to be productive. However, Freire and Soares (2010) understand that familiar companies are subjected to pressures that professional managers do not find when making a decision, because family relationships, besides supporting high emotional loads, are essentially loaded with conflicts that are not apparent, that to the smallest signal of organizational stress, explode beyond the explosive potential of the real problem. The authors, yet, state that "the flexibility and the result of the business management [...] go through the capacity of the family of dialoguing and trusting [...] one wants to teach everything one knows or has built up to the moment and, the other, wants to prepare himself/herself to what is coming, the way family members trust and dialogue is reproduced in the company (Freire \& Soares, 2010: p. 718)”.

Machado (2005) states that the family notion involves a complexity, as different forms coexist in the same culture, representing a differentiated composition of the nuclear and the patriarchal family, for both their members and for the redefinition of the familiar roles and for the new power distribution. The familiar dynamic acquires new shapes as to the composition and distribution of power, distance between generations and family size. These modifications in size and constitution of the familiar company are reduced with a smaller number of descendants. Still, according to the author, cases of familiar companies that have only one successor and that are sold because the successor does not intend to go on with the business are not rare. On the other hand, if the extensive family is the result of successive marriages, the cases in which the familiar company is the workplace for both the descendants of the first wedding and for the descendants of the second one and the aggregates are not a few, greatly increasing family involvement in the company.

However, concerning the managers of companies in which successors cannot be identified, the scenario is 
different. Thinking about finitude brings uncertainties. It can be understood that the managers who do not have successors present unanswered questions that cannot be elucidated when thinking about the finitude and the relationship with the company. The perspective that this subject will have to make a decision that he still does not know what it is becomes clear, because he realizes that this time is still far from the present, as observed in the following quotes:

[MWOS-2] [...] it is not easy having people working with you. People are very difficult. If I leave here it is better to close than leave someone working here. The person will cheat you in the business. In the future I plan to let someone manage the business and if someday my daughter wants to sell and put someone to work here, it is all right.

[MWOS-1] The descendants even got to work in the company, but [son's name suppressed] does not like it and went to another field [...] He is preparing himself because he wants to work in the diplomatic area. And [daughter's name suppressed] when she graduated we did not even imagine, because she has a degree in dentistry. So, you know, that broke us.

Paulo (2009) points out that there are cases in which succession is already planned. The chosen ones to continue the management are the sons and it is possible to define that the condition for succeeding is working in the company. However, not knowing if there will or will not be a successor makes it impossible to conclude about the competences that this subject must have and what his situation in the future will be, as manager of the company.

Zache, Schmitt and Gielnik (2012) indicate that the gender contributes for the decision about the succession, thus being a mediator between the successor's age and the familiar company. The results of their study showed that the age was positively related to the gender, which in turn positively influences the familiar succession. The data suggest that gender measures the relationship between age and familiar succession, becoming an important psychosocial factor for comprehending aging, career and succession in familiar businesses environments.

\subsection{Descendants' and Manager's Academic Background}

The data showed that the descendants' academic background is associated to personal training and titling, that is, to the managers'. For one of the managers without successor the association is present when he refers that he started working in a field in which he did not have much knowledge and to serve customers he had to take many courses, later on he mentions that his son and his daughter are studying and seem to have defined professional objectives.

[MWOS-1] We didn't have experience in the field, so we had to take several courses, because the client wants to get to the store and have certainty of what he is hearing.

This association can be identified through two biases, on one side the importance the manager gives to the academic background as a resource to be used in favor of the descendants' choice of professional activity. And, on the other hand, the recognition of the need for capacitation and qualification, in order to perpetuate the familiar company.

[MWS-2] [...] I told them we should go and sign up for a course of sebrae and take some courses, thus maybe we could improve ourselves, I didn't take any, besides paint ones.

[MWOS-3] [...] I have a degree in economics [...] My daughter sometimes asks me if I need help, she works as an intern in another company [...] she is very helpful, I answer "perhaps", I don't if it is the moment or not, I got rather confused. My father was an accountant, an excellent accountant. I tried working in the area, but it was not my field.

Paulo (2009: p. 67) highlights two aspects in the perspective of preparation for the succeeded, one in the aspect of graduation as a way to acquire technical knowledge for determined areas and another one, emerging from the know-how that is acquired by working experience. About these two ideas the author denotes:

The path is not, though, the separation between these two factors as conflicting and opposing ideas, but as realities that complement each other in a world increasingly more global and competitive. Graduation has, thus, to be part of our days continuously. Only by conciliating academic background and operational know-how will the successors be able to become real managers in the future, otherwise it will become ever more difficult to survive in the contemporary professional environment.

Oliveira, Albuquerque and Pereira (2012) state that the professionalization would be a possibility of forwarding the problems deriving from the company-family relationship, for it inserts a professional manager that is not 
a family member as an efficient way of conducting the company. According to the authors, the succession and the professionalization process of the familiar company demands changes in the property and control structures of these businesses, which imply the reconfiguration of the power relations.

\subsection{Leisure, Free Time and Management Problems}

An important data indicated in the analysis is the fact that the free time for leisure in related to the problems of the familiar company. The managers from both the MWS and the MWOS groups refer to the possibilities of performing leisure activities only when in absence of company problems, and because of that, many times the desired time to rest and relax cannot be reached by them and they make future plans aiming greater leisure opportunities.

[MWS-2] [...] My idea is that at this time of the day I want to go to the country house and return tomorrow at noon, help him (the son) at what he doesn't know, in his performance. I have to give him a hand too, otherwise who is going to give him a hand. We have a busy life, in my job I have to promise thing and meet them. I can't let thing get delayed.

Our activity is not the kind of activity that the client uses only during the business hours, if he has a question he is going to call you. In my leisure time [MWS-3] — I'm trying to work until Thursday night, then go to (name of the park was suppressed) and stay there during the weekend. It has been three years since I bought it (the house at the park), but I managed to do this three times. So, I haven't been able to do this much. But it is a target and I want to manage to do this.

The reason why managers can't resign from the company's activities and why the responsibility for the management problems rely on them can be comprehended in the fact that, according to Freire and Soares (2010), in familiar companies delegating deciding power is difficult, mainly when it is still administered by the founder, who resists to resigning the control of the company. Paulo (2009) points out that in the companies where it is not defined if there will or not be a successor, it is not possible to conclude about the competences the latter must have in order to assume the manager role, and in the one where the situation is already defined regarding the future, the main condition for succession is to work at the company.

\subsection{Living and Aging Process and Family Problems}

When the topics related to living and aging, it is associated to the wife and descendants. This enables the comprehension that these familiar ties are sources of safety, minimizing the anxiety that is generated by the thoughts related to aging.

[MWS-1] Regarding my health, I need to be careful, it is hard to tell because if I catch the flu and I don't recover from it very well, it is not a young person that can get healed (laughing) When I say I'm 80 it gets dangerous. I was supposed to have thrown a party celebrating our $60^{\text {th }}$ wedding anniversary, but my health was not very well and my wife was not ok in those days so we didn't do anything. We threw a party in our $50^{\text {th }}$ wedding anniversary. In our $60^{\text {th }}$, we were going to have the party at Panoramico, and invite around 150 people, but when I realized that, I was too tired and we didn't do anything. Nowadays a marriage that lasts 60 years is rare.

[MWS-3] I am 51 years old, I have been married for 27 years and my plan whenever my children have their degrees, I still plan to manage the company until I am 60, then I would like to leave Passo Fundo and live on the beach.

[MWOS-1] In the free time we hang out with the family, we travel. My wife and I go out for dinner. Now, you know, I want to get old, but I want to get to the age of 80 with a healthy life without depending on anyone. Good health and this independence.

Freire and Soares (2010) state that the company is a family issue and the latter interferes in the decisions of the former and vice-versa. In the succession generally the successor is one of the descendants and there is a resistance on the part of the manager to resigning from the company, and this resistance is steeper when it is related to the founders. The same authors found that this fact is more evident when the companies are in the second generation, and the current manager experienced the company's founder resignation. Thinking about diminishing eventual misunderstandings with the family, we can cite Oliveira et al. (2012), for they state that the option for the professionalization of the management represents, in the company, an alternative to minimize possible tensions resulting from the family growth and eventual disputes for the management positions amongst the members. 
Paulo (2009: p. 71) asserts in his research, that a good manager needs to have a strong framework of values and, besides that, needs to accept the values of others. As a matter of fact, as the manager, the relationships occur not only with the employees, but also with clients, with suppliers and with partners, all of them with distinct behavioral referrals. Thus, the manager must format all these behavioral referrals in order to maintain a good relationship with all of them and, therefore, manage the company emotionally supported.

\subsection{Personal Health and Succession}

There is a relation between the subjects' narratives regarding the theme succession and the questions related to health, that is, the absence of health becomes a factor that triggers the idea and the possibility of succession. For the managers without successors and that perceive the conclusion of the activities without the idea of continuity, a bigger difficulty arises, planning the life without the company, and while their health permits, continue working. As observed in following quotes:

[MWOS-3] I don't plan to stop working so soon. As long as I am healthy and able to work, I don't ever want to stop, ever.

[MWOS-1] The descendants even say "dad mom stop working, you are old", but we don't perceive that.

However, for the subjects that count on having successors in the familiar company, this correlation can be perceived differently, given that even when healthy they think of diminishing and altering the activities in the company to provide and favor the succession, which can be evidenced in the following example:

[MWS-2] Certainly, if I retire I will have to continue working anyway. But I will take it easy, he (son) will be in charge. When I retire, I plan to reduce the workload a little.

Oliveira et al. (2012) state that the majority of the authors share the idea of succession as a journey, in which the definition of the individual's destiny ends dreams shared by the family, built over decades and which meet the expectations, unconscious at many times, about the trajectory and the performance of the successors. According to Freire and Soares (2010), succession is seen as a process of oxygenation of the management, and the challenge for the companies that are in this process is to find a way to minimize the effects of personal resistances that this process provokes in the organization as a whole. The resistances need to be seen as natural things that will be present in the process and managed systematically, because if ignored, the blockage of learning through the growth of damaging conflicts in the achievement of the results intended will be perceived.

What can be seen, according to the studies of Pinto and Couto-de-Souza (2009), is the strong influence of the directors' personalities, with their centralizing management in implanting new processes, and also, it must be mentioned the resistance of members of the company regarding changing, which is perceptible during the interviews and the authors suggest that new researches be made in this areas, pointing to the relations between the personality of the manager that is in charge of the changing conduction, and his/her familiar ties with the patriarch, for organizations going through succession.

\section{Conclusion}

Studying human aging gives the opportunity of a new look at the living process and opens paths for us to look at new possibilities at aging. When we start to understand living and aging, we stop thinking that the beautiful has to be the new, and we start perceiving that those who don't walk so fast and are not rushing anymore also have dreams, fears and aspirations.

This study directed the research toward the subject and its perceptions, feelings and life expectancies to understand human beings as constructs of their subjectivity, interactions, responses and significances. Therewith, it can be taken into account that the managers of familiar companies project the old age as a slowed-pace routine, without the rush of everyday life, but with some activity. Since the complete separation from the professional activities is far from becoming a viable option and even farther is it the managers' wish.

These subjects find in the job tight ties to life. Their familiar and professional relationships at many times are confounded, as are the roles related to being a father, entrepreneur, husband and administrator.

It is worth considering that the manager without successor lives uncertainties about the business's future. He plans to work as long as his health allows and finds personal realization in the professional activity. However, there are indications that the manager with successor, endeavors in the perpetuation of the company, not only in what concerns the constituted company and its physical structure, but especially to the personal values and the way of managing. The manager seeks to transmit his culture to the successor, and expects the latter to manage 
similarly to his already instituted model. That, certainly, sometimes, turns into conflicts with the family members that are trying to set their own and unique space in the company.

\section{Authors' Contribution}

M. L. M. and A. P. projected the experiment; M. L. M. performed the interviews; M. L. M. and A. P. analyzed the data; M. L. M. wrote to the journal. All the authors discussed the results. The authors declare that there is no financial interest. Correspondence and material orders must be directed to M. L. M.

\section{Note}

MWS: manager with successor; MWOS: manager without successor.

\section{References}

Freire, P. S., Soares, A. P., Nakayama, M. K., \& Spanhol, F. J. (2010). Processo de sucessão em empresa familiar: Gestão do conhecimento contornando resistências às mudanças organizacionais. Revista de Gestão da Tecnologia e Sistemas de Informação, 7, 713-736.

Machado, H. V. (2005). Reflexões sobre concepções de família e empresas familiares. Psicologia em Estudo, 10, 317-323. http://dx.doi.org/10.1590/S1413-73722005000200019

Martins, A., Maccari, E. A., Campanario, M. A., \& Almeida, M. I. R. (2008). Empresa familiar e as dificuldades enfrentadas pelos membros da terceira geração. Revista de Ciências da Administração, 10, 30-54. http://dx.doi.org/10.5007/2175-8069.2008v10n22p30

NVivo 10 (2010). Manual. http://www.qsrinternational.com

Oliveira, J. L., Albuquerque, A. L., \& Pereira, R. D. (2012). Governança, sucessão e profissionalização de uma empresa familiar: (Re)arranjando o lugar da família multigeracional. Revista Brasileira de Gestão e Negócios, 14, 176-192.

Paulo, D. N. A (2009). Empresas Familiares em Portugal: “Sucessão Competente”. Ph.D. Thesis, Lisboa: Universidade Técnica de Lisboa.

Pinto, M. C. S., \& Couto-de-Souza, C. L. (2009). Mudança organizacional em uma empresa familiar brasileira. Revista de Administração Pública, 43, 609-634. http://dx.doi.org/10.1590/S0034-76122009000300005

Schutz, A. (1979). Fenomenologia e relações sociais. Rio de Janeiro: Zahar.

Zache, H., Schmitt, A., \& Gielnik, M. M. (2012). Stepping into My Shoes: Generativity as a Mediator of the Relationship between Business Owners’ Age and Family Succession. Aging \& Society, 32, 673-696. http://dx.doi.org/10.1017/S0144686X11000547 
Scientific Research Publishing (SCIRP) is one of the largest Open Access journal publishers. It is currently publishing more than 200 open access, online, peer-reviewed journals covering a wide range of academic disciplines. SCIRP serves the worldwide academic communities and contributes to the progress and application of science with its publication.

Other selected journals from SCIRP are listed as below. Submit your manuscript to us via either submit@scirp.org or Online Submission Portal.
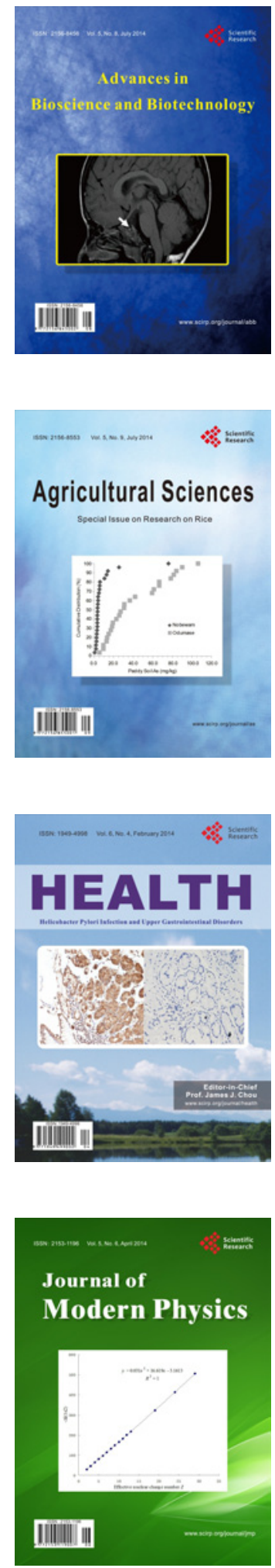
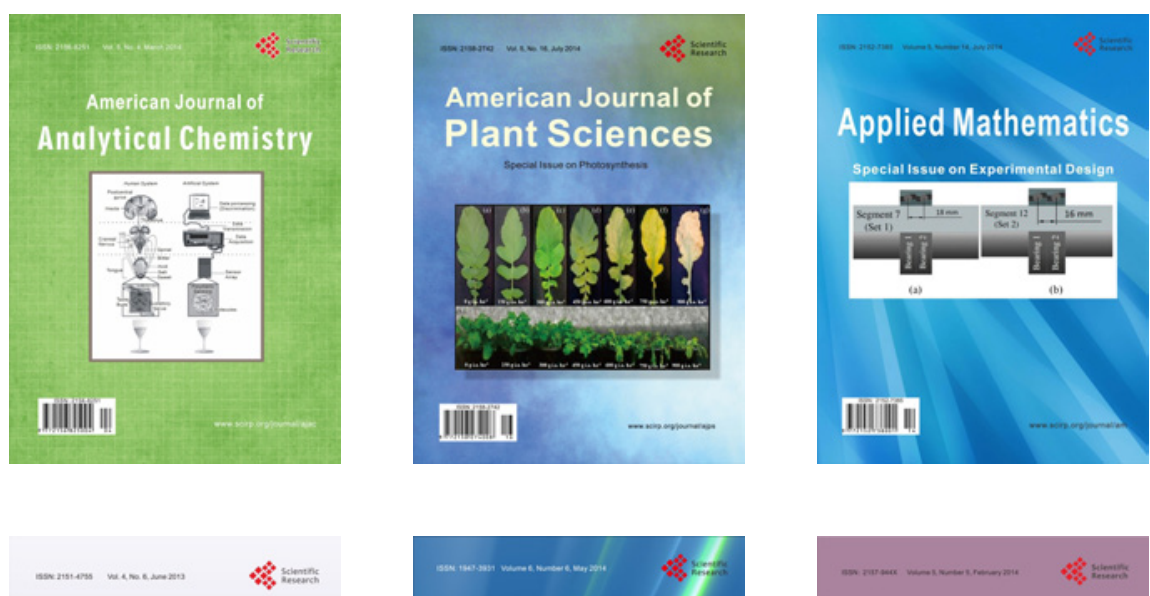

Creative Education
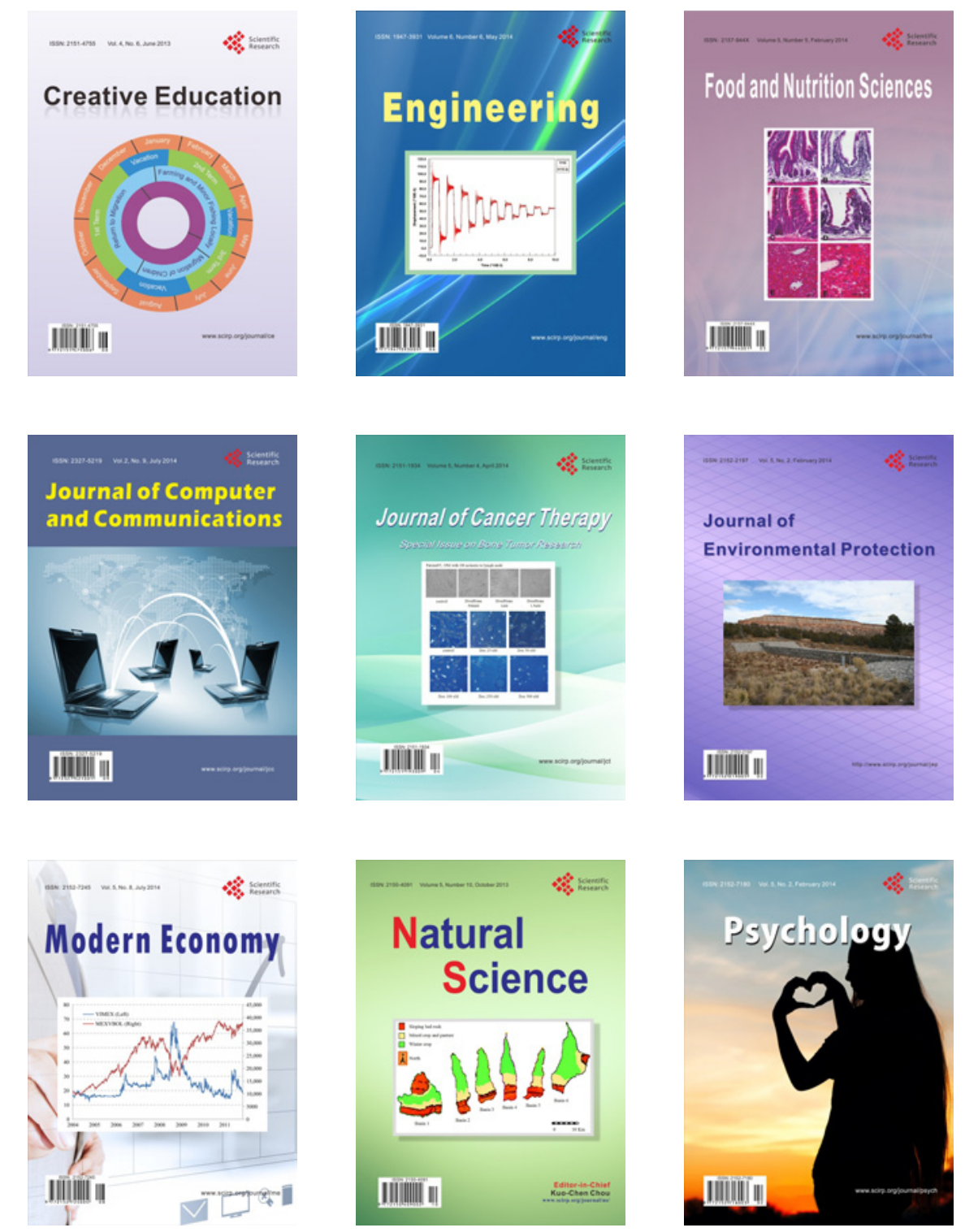